\title{
Effect of different preparation procedures on the ultrastructure of gonococci
}

\author{
W. GEBHART,* W. JURECKA,* J. SÖLTZ-SZÖTS,* J. THURNER,* A. ELLINGER,† \\ AND K. KITZ† \\ From the *Epidemiology Unit of the Department of Dermatology II; and the †Institute for Micromorphology \\ and Electron Microscopy, University of Vienna, Austria $\ddagger$
}

SUMMARY Culture samples of Neisseria gonorrhoeae and Escherichia coli were studied by transmission and electron microscopy to evaluate the effect of different preparation procedures on the pilation of these organisms. Unfixed as well as fixed bacteria showed only few, long, filamentous appendages when investigated in ultrathin sections, negatively stained specimens, or critical-point dried preparations. Snap-frozen specimens of $E$. coli showed many short and thin pili after being shadowed with carbon and platinum whereas those of $N$. gonorrhoeae showed only some type-C-like pili. Thus, the number and morphological appearance of pili appear to be greatly influenced by the preparation techniques used for study by electronmicroscopy. Conclusions as to the type and the infectivity of a bacterial strain can, therefore, not be based on purely morphological criteria.

\section{Introduction}

The physical, chemical, and adhesive properties of pili in Enterobacteriacea have been well documented in the past (Brinton, 1965; Duguid et al., 1966, 1969). Consequently, it has been recognised that pili or morphologically similar structures occur in a wide range of Gram-negative organisms.

Many investigators have studied the surface of Neisseria gonorrhoeae in recent years. The presence of pili on Kellog type 1 and type 2 gonococci as well as their absence on other non-virulent types (Jephcott et al., 1971, Swanson et al., 1971) have stimulated discussion and theories. Recently, Haustein and Uehrlings (1976) suggested that non-pilated gonococci were important epidemiologically, since they had found non-pilated organisms in $20 \%$ of asymptomatic cases of gonorrhoea. The negative-staining technique had been used in these investigations. Using the same technique, however, we have seen differences in the number and in the appearance of pili-even in samples from the same culture-depending on the dye applied for the negative-staining.

†In co-operation with the Ludwig Boltzman Institute for Reasearch on Infectious Venero-dermatological Diseases.

Address for reprints: Professor J. Söltz-Szöts, Allgemeines Krankenhaus des Stadt Wien, II Universitats-Hautklinik, 9 Alserstrasse 4, 4-1090 Vienna, Austria

Received for publication 16 November 1978
We have therefore carried out a controlled study on gonococcal pili using different preparation procedures but following the same two-day culture techniques as Haustein and Uehrlings (1976) had used in their study.

\section{Material and methods}

Two-day-old cultures of gonococci cultured on Thayer-Martin agar and one-day-old cultures of Escherichia coli cultured on Bouillon agar were used for this study. For preparations of the bacteria the following techniques were used simultaneously:

(1) Small pieces of agar with bacterial colonies were fixed with buffered glutaraldehyde and osmium tetroxide $\left(\mathrm{OsO}_{4}\right)$, dehydrated with alcohol, and embedded in Epon 812.

(2) Gonococci and coliform bacilli grown on culture plates were placed in glutaraldehyde with a platinum loop, gently centrifuged, postfixed with $\mathrm{OsO}_{4}$, and embedded in Epon 812. Ultrathin sections of cultures by both methods were stained with uranyl acetate and lead citrate and examined in a Philips EM 200 electronmicroscope.

(3) Glutaraldehyde-fixed and unfixed bacteria were placed on Formvar-coated electronmicroscope (EM) grids and stained with uranyl acetate or phosphotungstic acid (PTA). To place the bacteria on the EM grids two 
different techniques were used: (a) bacteria were suspended in water, Ringer solution, or glutaraldehyde and a drop of these suspensions was allowed to dry on the grids; and (b) the coated EM grids were directly put on the bacteria growing on the culture plate and after being dried, stained, and carefully washed in distilled water the preparations were examined in a Zeiss EM 9 electronmicroscope.

(4) For scanning electronmicroscopy the criticalpoint drying method described by Fromme et al. (1972) was used. Bacteria were fixed by suspension in glutaraldehyde. After filtration of this solution through a millipore filter the bacteria remaining on the filter were dehydrated with alcohol and transferred in Freon 11 and then in Freon 13 (pressure 39.36 $\mathrm{mm} \mathrm{Hg}$, temperature $28 \cdot 8^{\circ} \mathrm{C}$ ). After drying and decompression the bacteria were sprayed with carbon and gold and examined in a Cambridge scanning electronmicroscope.

(5) EM grids with unfixed bacteria on the Formvar film were frozen in liquid nitrogen. These preparations were dried in a modified Leybold EPA 100 freeze-etching machine at $-90^{\circ} \mathrm{C}$ and a pressure of about $2 \times 10^{-r}$ millibars. After complete drying the grids were shadowed with a thin layer of carbon and platinum at $-110^{\circ} \mathrm{C}$ and $2 \times 10^{-7}$

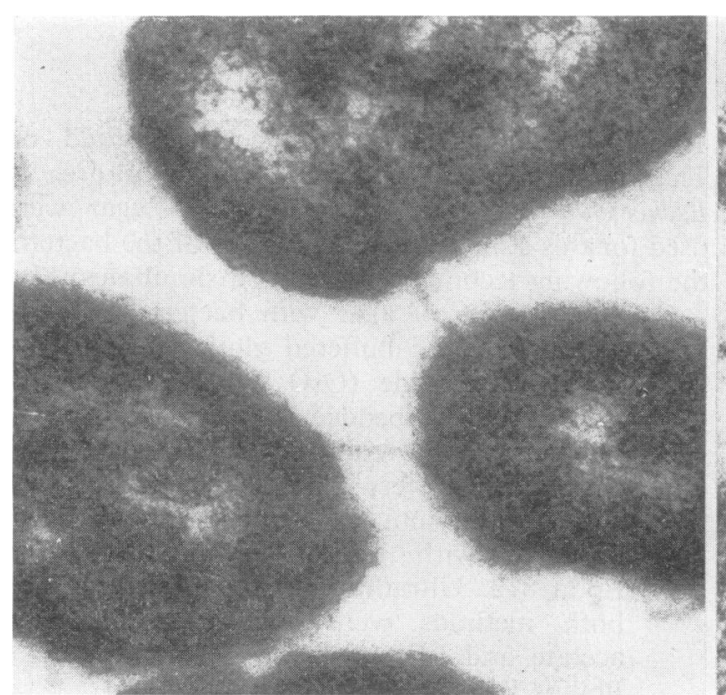

(a) millibars. An angle of $15^{\circ} \mathrm{C}$ was chosen for the coating procedure in order to achieve sufficient contrast. Investigation of these specimens was performed in a Philips EM 200 electronmicroscope.

\section{Results}

TRANSMISSION ELECTRONMICROSCOPY OF ULTRATHIN SECTIONS

Between vacuolised and autolytical cells and cell membrane fragments well-preserved gonococci or coliforms could be seen. It was very difficult or nearly impossible in our preparations, however, to trace a long and thin, more or less unorientated filament like a pilus in an ultrathin section. Some osmiophilic filamentous structures or fragments of filaments could be seen extending between the cells or originating from their outer surface (Fig. $1 a, b)$.

\section{TRANSMISSION ELECTRONMICROSCOPY OF}

NEGATIVELY STAINED PREPARATIONS

With negatively stained preparations nearly identical results could be seen after the sections had been stained with uranyl acetate or with phosphotungstic acid. In the preparations of gonococci usually $20 \%-30 \%$ of the cells had long filamentous appendages corresponding to type A pili (Fig. 2a). These pili mainly stood in bundles and had a

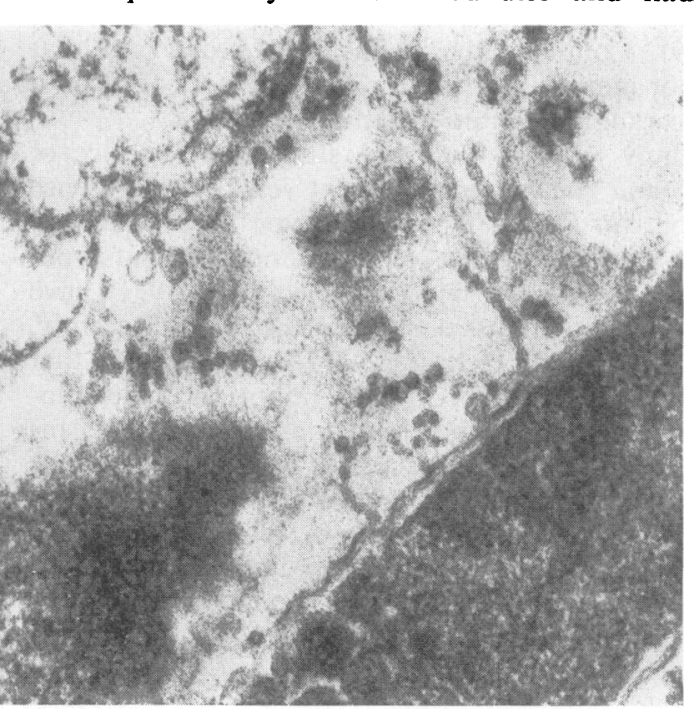

(b)

Fig. 1 Transmission electronmicroscopy of ultrathin sections of (a) gonococci and (b) coliform bacilli fixed with glutaraldehyde and osmium tetroxide: (a) some thin filaments are visible extending from the outer surface of one organism to neighbouring bacteria ( $\times 65000$ magnification); (b) several pearl-string-like fibres originate from the outer cell wall ( $\times 52000$ magnification) 

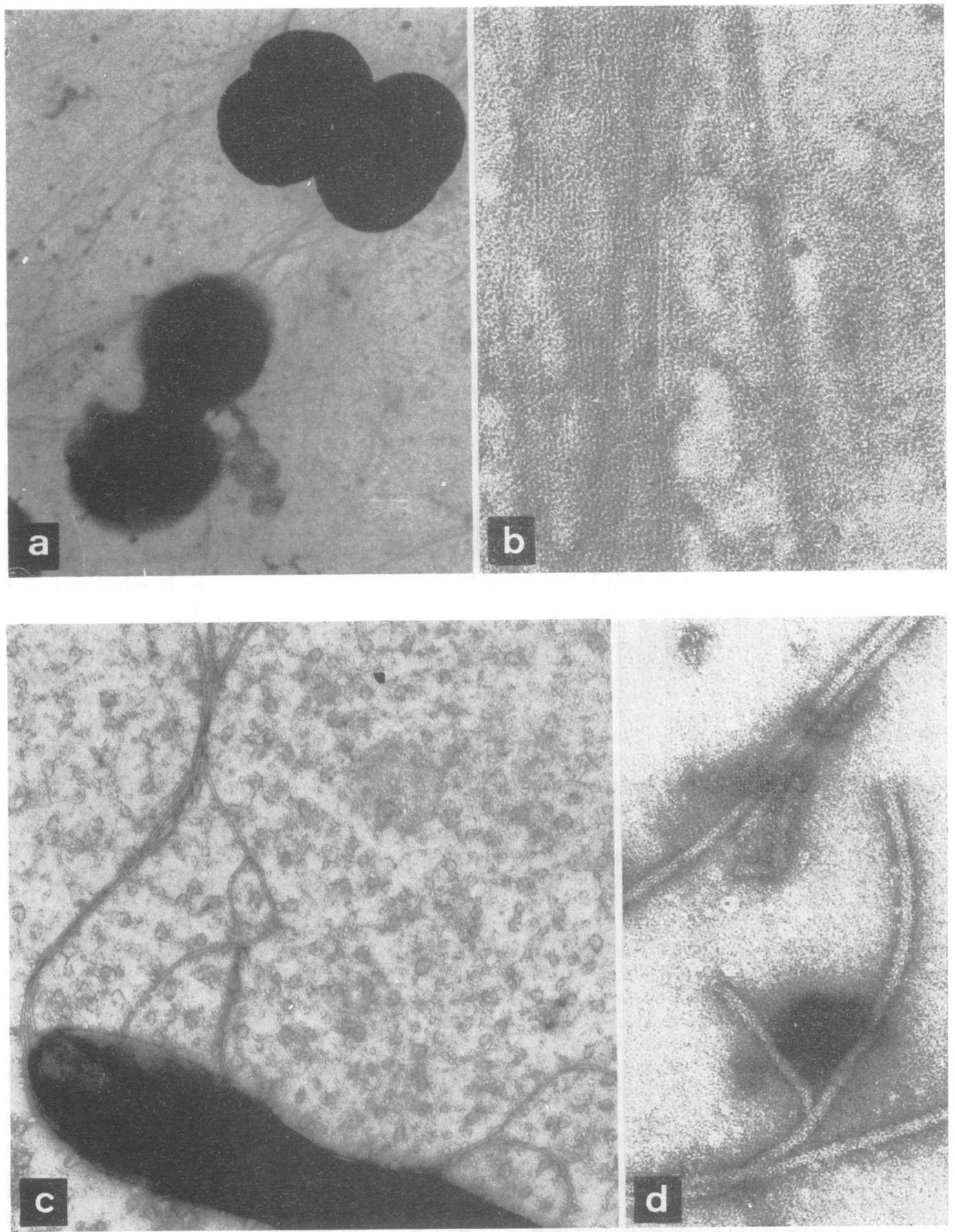

Fig. 2 Unfixed gonococci $(a$ and $b$ ) and glutaraldehyde-prefixed coliforms ( $c$ and d) negatively stained with PTA: (a) numerous long bundles of thin filaments are present around the organisms $(\times 24000$ magnification $) ;(b) a$ number of parallel membranes arranged in bundles is visible $(\times 100000$ magnification $) ;(c)$ well-defined, long, curved pili are present ( $\times 25000$ magnification); (d) cross-overs and ramifications of pili are shown $(\times 140000$ magnification). 
diameter of about $10 \mathrm{~nm}$ and a length of several $\mu \mathrm{m}$. The same preparations frequently also exhibited bundles of parallel membranes along these aggregates of pili, which, because of their thinner diameter, corresponded to structures described as type B pili (Fig. 2b).

Simultaneous preparations from pilated $E$. coli strains also showed very long pili. They were curved and irregularly arranged; at a higher magnification they showed some crossovers (Fig. 2c, d).

\section{SCANNING ELECTRONMICROSCOPY OF \\ FREEZE-DRIED PREPARATIONS}

With scanning electronmicroscopy the critical-point dried preparations of gonococci showed no recognisable pili. Only rarely were some thin fibres seen extending from one organism to a neighbouring one (Fig. 3) similar to the structures present in the ultrathin sections.

\section{T RANSMISSION ELECTRONMICROSCOPY OF SHADOWED PREPARATIONS}

Finally, in the platinum-carbon shadowed preparations of the samples mentioned above no type A pili could be detected at all (Fig. 4a). Only a few cells showed single long pili with a knob at the end (Fig. 4b). These structures have been described as type C pili (Novotny and Turner, 1975). Most of the gonococci had no recognisable pili, however,

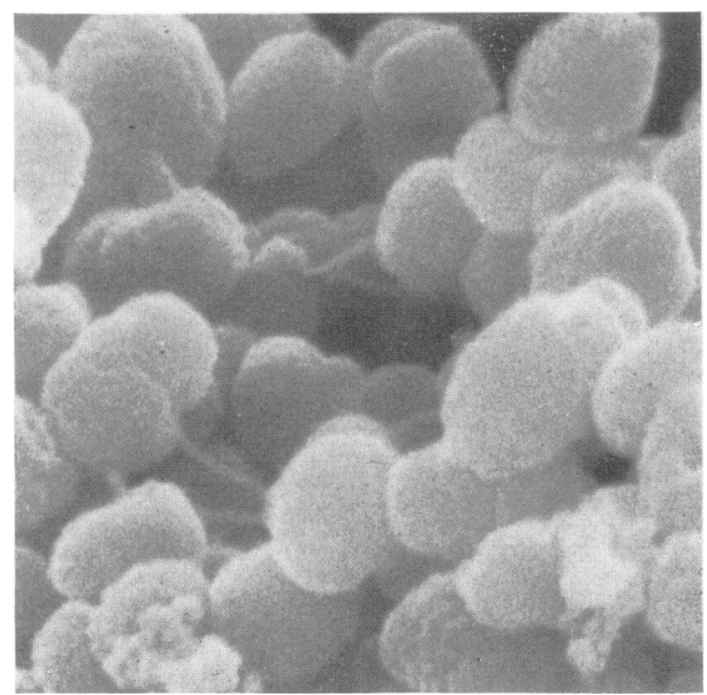

Fig. 3 Scanning electronmicrograph of critical-point dried gonococci on millipore filter; only a few filamentous structures are present between the cells $(\times 19000$ magnification) but only a pronounced outer membrane (Fig. 4a). In preparations of $E$. coli more very short and thin pilar structures could be seen all over the surface of the cells (Fig. 5a, b). These were also seen wrapped around the cells and, occasionally, at some distance from the membrane (possibly after having lost their contact with the cell itself).

\section{Discussion}

Our investigations into the comparative effects of different preparation procedures on the ultrastructural appearance of gonococci and coliform bacilli gave varied results. Transmission electronmicroscopy of ultrathin sections gave the impression that only occasionally was a pilum tangentially cut, but it was never possible to follow these structures over a longer distance. Thus, this technique itself is not suitable for the evaluation of pilar structures at all. Scanning electronmicroscopy of critical-point dried material was also not satisfactory in our preparations.

Negative-staining mainly produced long bundles of type A pili, after staining of gonococci and coliforms with phosphotungstic acid and uranyl acetate. The same cultures, however, exhibited only type $\mathbf{B}$ and $\mathbf{C}$ pili or even no pili when examined after freeze-drying and shadowing with platinum.

These discrepancies in the number and morphological appearance of pili indicate strongly that the pilation of both $N$. gonorrhoeae and $E$. coli is greatly influenced by the mode of preparation. Similar variations were seen by Duguid et al. (1966) when different culture conditions were applied. These authors discussed their findings in relation to the changing external factors and to ageing processes and the infectious potentials of the bacteria. Our results show that preparation conditions also play an important part in the ultrastructural appearance of the outer bacterial zone.

\section{Conclusion}

From these experiments and a consideration of the factors influencing the pilation we were not able to endorse the opinion that simple electronmicroscopical examination of negatively stained gonococci permits definite determination of the strain investigated. The fact that (according to Haustein and Uehrlings) $20 \%$ of asymptomatic cases of gonorrhoea are caused by non-pilated organisms does not necessarily indicate infection with type 3 or 4 gonococci. Too many factors influence the morphological appearance of pili, and many more compartments of the glycocalyx, besides the pili, are necessary to 
build up a suitable environment for the multiplication of the bacteria and to form the aggregates called 'infection units' (Novotny et al., 1975).

Electronmicroscopical examination of microorganisms has made an important contribution to our present knowledge of bacterial structure, and further progress is to be expected. Further standardisation of the preparation techniques, however, are necessary before typing and quantification of gonococcal pili can be used to determine the infectivity of the strain on a purely morphological basis.
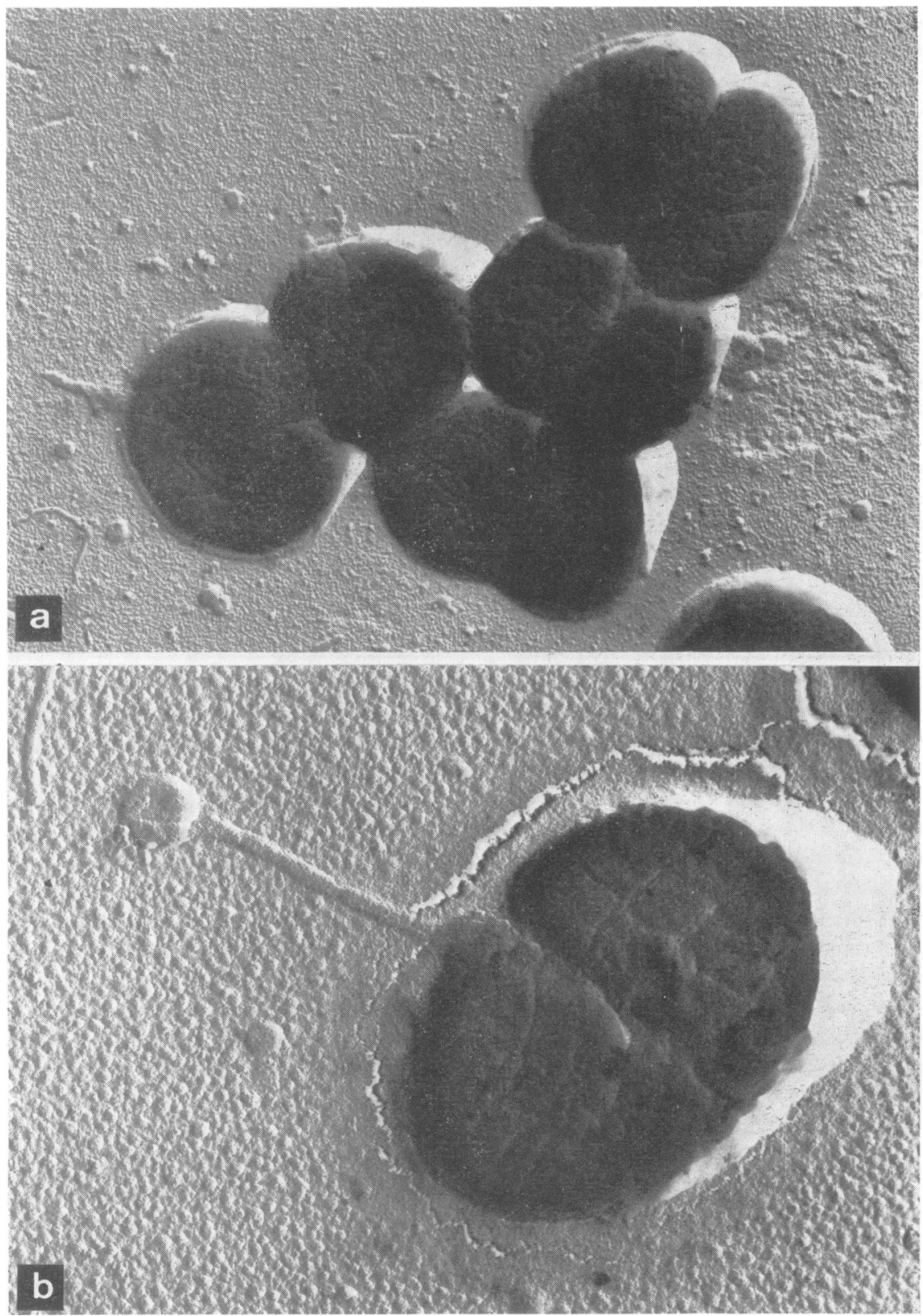

Fig. 4 Carbon-platinum shadowed preparations of snap-frozen gonococci: (a) no pili can be recognised in this specimen ( $\times 20500$ magnification); (b) a thick filament with a knob at its end seems to extend from the cell $(\times 51500$ magnification) 

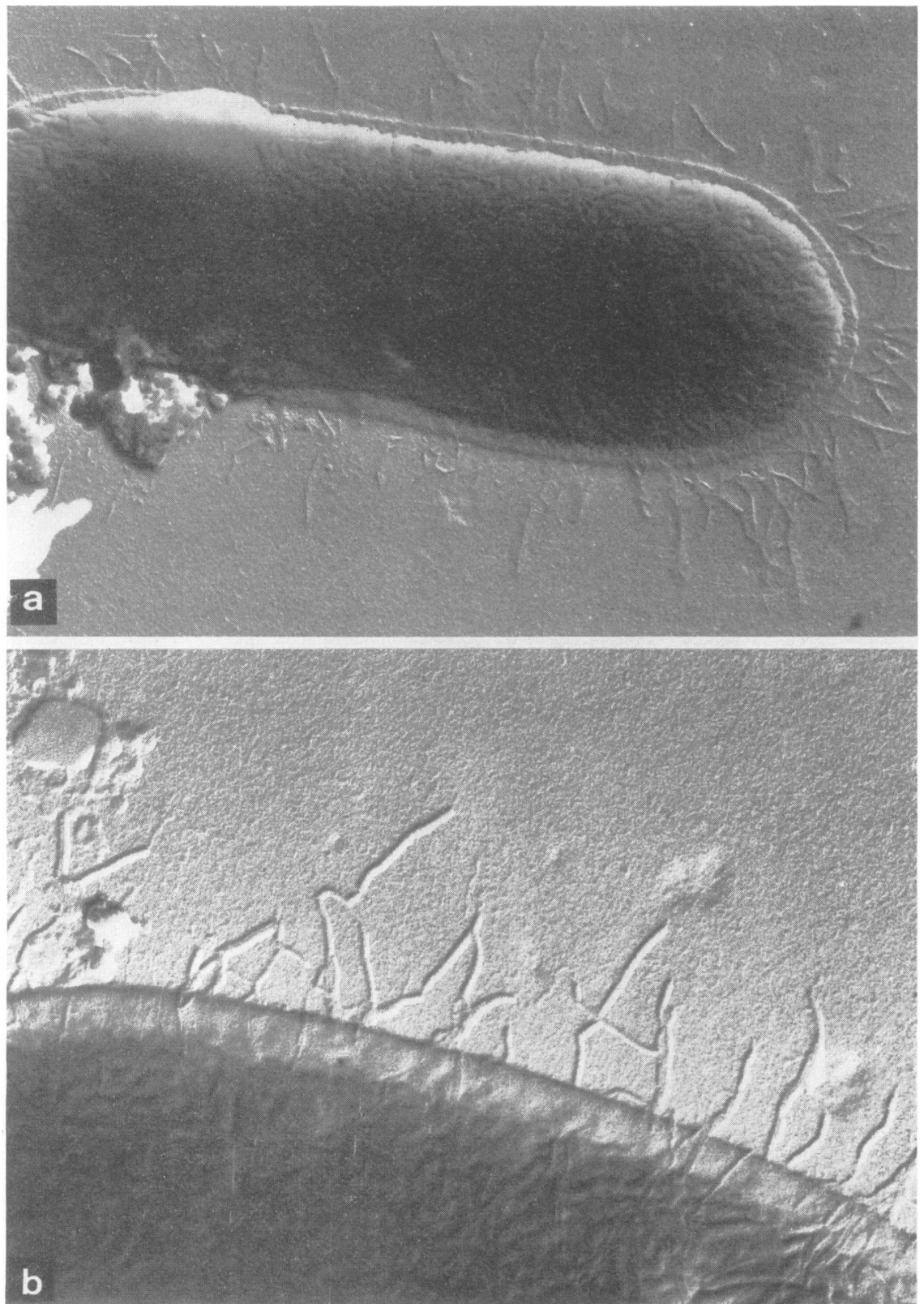

Fig. 5 Carbon-platinum shadowed preparations of snap-frozen coliform bacilli: (a) numerous, short and thin pili are visible ( $\times 27000$ magnification); (b) numerous pili covering the surface are shown ( $\times 61500$ magnification) 


\section{References}

Brinton, C. C. (1965). The structure, junction, synthesis and genetic control of bacterial pili and a model for DNA and RNA transport in Gram-negative bacteria. Transactions of the New York Academy of Sciences, 27, 1003.

Duguid, J. P., Anderson, E. S., and Campbell, I. (1966). Fimbriae and adhesive properties in salmonellae. Journal of Pathology and Bacteriology, 92, 107.

Duguid, J. P., and Campell, I. (1969). Antigens of the type A fimbrae of salmonellae and other enterobacteria. Journal of Medical Microbiology, 2, 535.

Fromme, H. G., Pfefferkorn, G., Pfantsch, M., Bystricky, V. (1972). Erfahrungen mit der 'kritischen punkt'-trocknung als praparations-methode für die raster-elektronenmikroskopie. Beiträge zur elektronenmikroskopischen.

Haustein, U. F., and Uehrlings, I. (1976). Die asymptomatische gonokokkeninfektion. Dermatologische Monatsschrift, 162, 9.
Jephcott, A. E., Reyn, A., and Birch-Anderson, A. (1971). Neisseria gonorrhoeae. III. Demonstration of presumed appendages to cells from different colony types. Acta pathologica microbiologica Scandinavia $(B), 79,437$.

Novotny, P., Short, J. A., and Walker, P. D. (1975). An electron microscope study of naturally occurring and cultured cells of Neisseria gonorrhoeae. Journal of Medical Microbiology, 89, 413.

Novotny, P., and Turner. W. H. (1975). Immunological heterogenity of pili of Neisseria gonorrhoeae. Journal of General Microbiology, $89,87$.

Swanson, J., Kraus, S. J., and Gotschlic, E. C. (1971). Studies on gonococcus infections. I. Pili and zones of adhesion: their relation to gonococcal growth patterns. Journal of Experimental Medicine, 134, 886 